Institute of $\mathbf{F}_{\text {ood and }} \mathbf{A g r i c u l t u r a l}_{\mathbf{S}} \mathbf{S}_{\text {ciences }}$

\title{
Creating an Energy Efficient Room ${ }^{1}$
}

Marie Hammer ${ }^{2}$

Heating and cooling alternatives are not the only ways to save energy. Simple decorating and home furnishing principles can psychologically effect the temperature inside. You can alter the way a room feels to make it more comfortable by carefully selecting colors, furniture and accessories. In Florida, this usually means creating a cooler-looking room for warm weather.

\section{Heating and Cooling with Color}

Color has a powerful influence on emotions and feelings that can affect the indoor temperature. It can also stretch or shrink rooms, and make undesirable features disappear. Since color has a direct emotional and psychological effect on people, you can decorate your home to create an atmosphere that is cozy or cool, lively or serene, country or contemporary. Look at some of the ways you can make color work for you.

\section{Space, Color and Perception}

Color affects the perception of space. Light colors on walls, floors and ceilings make rooms appear larger and more open. Cool hues such as blue and green can also create an open, airy look. When rooms appear larger, they also seem cooler. Dark colors create a cozy feeling that makes a room feel smaller. Warm colors and strong intensities such as red, orange and yellow also create a warm atmosphere that makes you feel snug and secure. What can you do if you like bright warm colors but want to create a "cooler" room? Use neutrals -- white, beige, gray -- for the background, and use your favorite warm color in small amounts for accents.

\section{Lighting and Color}

Color affects the lighting used in a room. Dark colors absorb light, so rooms with walls, floors and furnishings in dark colors will require more lighting. This not only increases the amount of electricity needed to operate the lights, but also increases the amount of heat given off by incandescent lighting. During warm summer months this extra heat puts a burden on cooling the home.

Light-colored ceilings reflect more light than dark-colored ceilings, thus making the room brighter. Therefore, less artificial light is needed.

1. This document is FCS 3090, one of a series of the Department of Family, Youth and Community Sciences, Florida Cooperative Extension Service, Institute of Food and Agricultural Sciences, University of Florida. Publication date: August 2002. First published: August 1988. Reviewed: August 2002 Please visit the EDIS Web site at http://edis.ifas.ufl.edu

2. Written by Marie Hammer, former Professor, Housing/Home Environment, Department of Family, Youth and Community Sciences, Cooperative Extension Service, Institute of Food and Agricultural Sciences, University of Florida, Gainesville, 32611 and reviewed by Nayda I. Torres, Professor, Family and Consumer Economics, Department of Family, Youth and Community Sciences, Cooperative Extension Service, Institute of Food and Agricultural Sciences, University of Florida and Dale Dorman, Extension Housing and Environment Specialist - Emeritus, Cooperative Extension Service, University of Georgia. 
A lighter ceiling will also appear higher, so the room will seem larger and more open.

\section{Tips for Using Color}

Your perception of color is influenced by lighting, surrounding colors, the amount of light reflected by various textures, and the size of the color areas.

- A color is brighter when it is used on four walls of a room instead of just one.

- Colors look different in natural sunlight than under artificial light.

- $\quad$ Rough textures make a color look very different than smooth, slick surfaces. Compare black velvet with a slick, black vinyl upholstery fabric for an example of this.

- Colors look brighter when used with their complementary colors.

- Glare can be minimized by using a light color scheme, and reducing the contrast between lighter and darker surfaces. Texture and finish are also important in controlling glare. Generally, soft textures or dull finishes absorb light helping to reduce glare.

To create a cool effect in your Florida home, consider these suggestions when selecting room colors.

1. Keep the background walls, floors and ceilings light or neutral colored.

2. Use tints, or mixtures of a color plus some white, rather than bright colors for large areas in a room.

3. Use warmer, brighter, more intense colors for accessories and smaller areas.
Reactions to colors are primarily emotional, and quite varied. It is your perception and response to color that is important, and that should be considered when creating your energyconscious room.

\section{Designing a Comfortable Environment}

\section{Accessories and Furniture}

The amount and kinds of furnishings in a room will also affect your psychological perception of a room. A room that has several pieces of furniture, contains lots of print fabrics and wall coverings, has dark wood paneling, elaborate window treatments and lots of accessories and ornaments will appear to be warmer and cozier. A room with fewer furniture pieces, plain fabrics and wall coverings, simple window treatments, few accessories, and lots of living plants will appear cooler and more spacious. Research studies have found that volunteers who spent time in a sparsely furnished room felt cooler than they did in a fully furnished room even though the actual temperature of the room remained the same.

During the winter, quilts, hooked rugs, soft sculptures and soft, fuzzy pillows warm up an environment. To "cool" your home during the summer, fill baskets with ferns, hang light airy prints on the walls, add cool crisp pillow covers and use baskets or bowls of fresh fruit and vegetables.

\section{Furniture Design}

Chairs with high backs, enclosed arms and legs, and textured upholstery will be warmer than those with low backs, open arms and legs, and smooth fabrics. Furniture that allows air to flow through, such as wicker or cane chairs, will be cooler for Florida homes.

Slipcovers made of smooth fabrics can help you feel cooler in hot weather when they cover 
furniture with textured upholstery. Fabrics such as muslin, sheeting, canvas and chintz convey a "cool" image. In winter, quilted fabrics or those with napped or brushed surfaces convey a "warm" message and feeling.

\section{Room Arrangements}

Furniture arrangement is important for energy-conscious decorating. Sitting near windows can make you colder in the winter and warmer in the summer unless your windows are adequately protected.

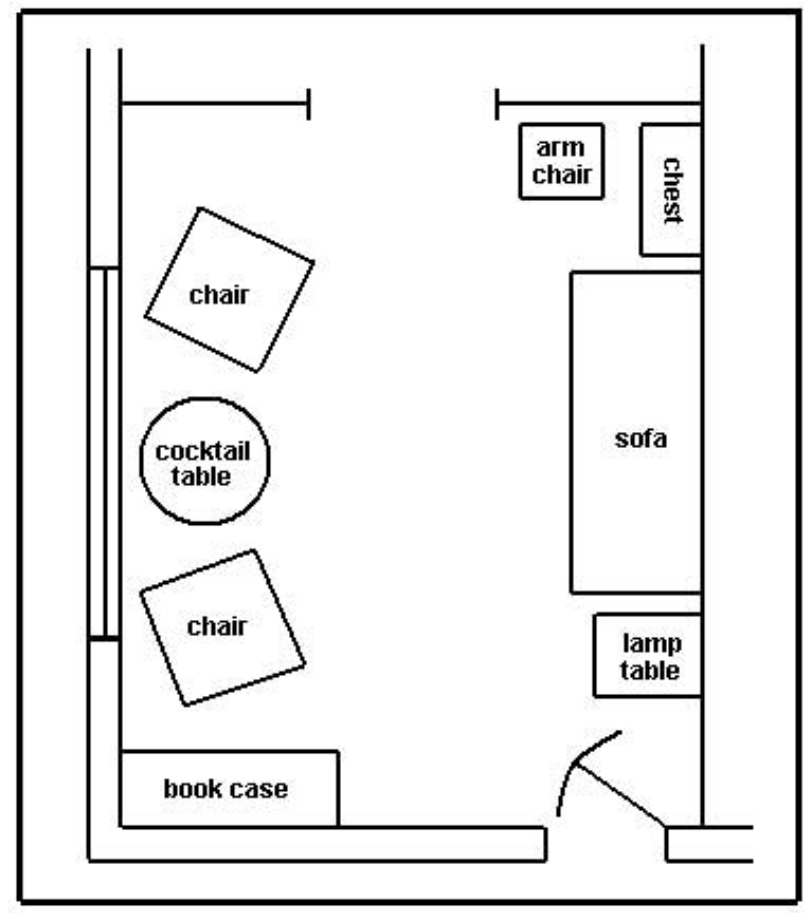

Figure 1. In summer, spread out furniture for a cooler look.
Arrange furniture to create a cozy conversation area away from exterior walls in the winter. During the summer, spread out the furniture for a cooler look.

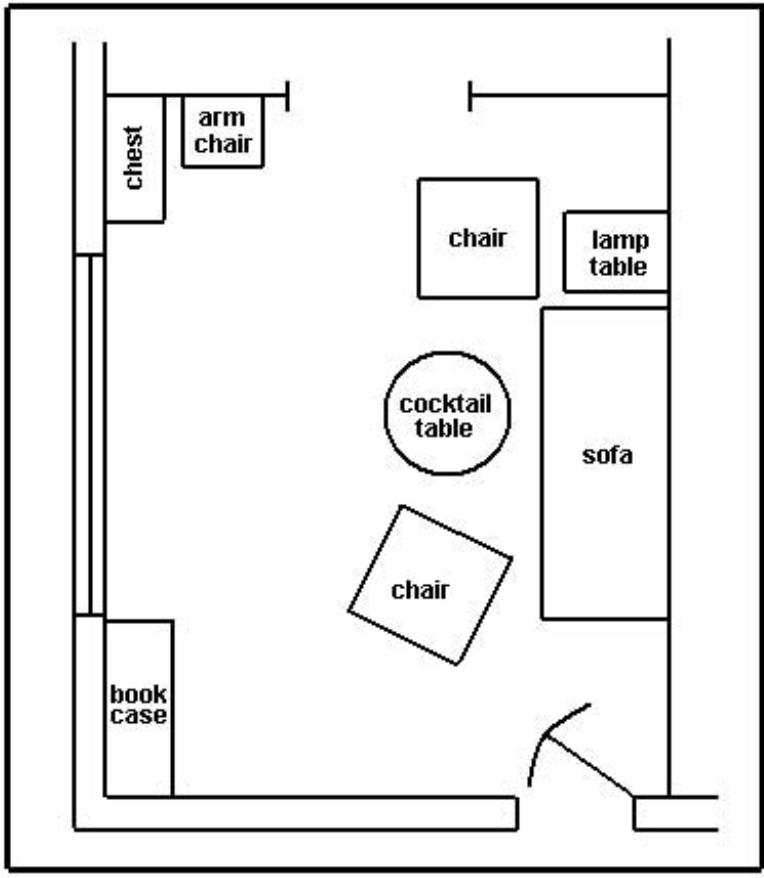

Figure 2. In winter, arrange furniture away from exterior walls.

Make the best use of your heating and cooling systems. Do not block heating and cooling vents with furniture or draperies. Deflectors can be added to vents to direct the flow of air and create good circulation. 